Genomic Classifier Augments the Role of Pathological Features in Identifying Optimal Candidates for Adjuvant Radiation Therapy in Patients With Prostate Cancer: Development and Internal Validation of a Multivariable Prognostic Model.

\author{
Deepansh Dalela \\ Henry Ford Health System \\ María Santiago-Jiménez \\ GenomeDx Biosciences
}

Kellofy thisestaf additional works at: https://jdc.jefferson.edu/radoncfp

HameDx Biosciences commons, and the Radiology Commons

kedfftes kainesw how access to this document benefits you Mayo Clinic

\title{
Rebbrymernetrod Citation
}

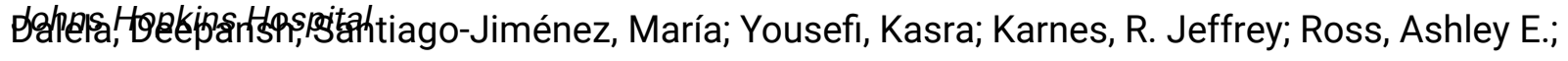
Den, Robert B.; Freedland, Stephen J.; Schaeffer, Edward M.; Dicker, Adam P.; Menon, Mani;

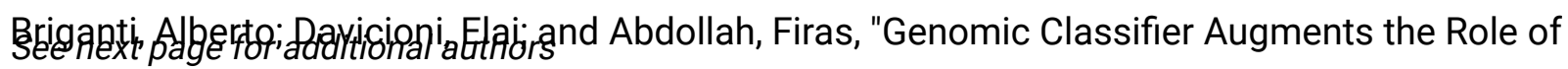
Pathological Features in Identifying Optimal Candidates for Adjuvant Radiation Therapy in Patients With Prostate Cancer: Development and Internal Validation of a Multivariable Prognostic Model." (2017). Department of Radiation Oncology Faculty Papers. Paper 96. https://jdc.jefferson.edu/radoncfp/96

This Article is brought to you for free and open access by the Jefferson Digital Commons. The Jefferson Digital Commons is a service of Thomas Jefferson University's Center for Teaching and Learning (CTL). The Commons is a showcase for Jefferson books and journals, peer-reviewed scholarly publications, unique historical collections from the University archives, and teaching tools. The Jefferson Digital Commons allows researchers and interested readers anywhere in the world to learn about and keep up to date with Jefferson scholarship. This article has been accepted for inclusion in Department of Radiation Oncology Faculty Papers by an authorized administrator of the Jefferson Digital Commons. For more information, please contact: JeffersonDigitalCommons@jefferson.edu. 


\section{Authors}

Deepansh Dalela, María Santiago-Jiménez, Kasra Yousefi, R. Jeffrey Karnes, Ashley E. Ross, Robert B. Den, Stephen J. Freedland, Edward M. Schaeffer, Adam P. Dicker, Mani Menon, Alberto Briganti, Elai Davicioni, and Firas Abdollah 
Author affiliations and support information (if applicable) appear at the end of this article.

Published at jco.org on March 28, 2017. Corresponding author: Firas Abdollah, MD, Vattikuti Urology Institute, Henry Ford Health System, 2799 W Grand Blvd, Detroit, MI 48202-2689; e-mail: firas. abdollah@gmail.com.

(C) 2017 by American Society of Clinical Oncology

0732-183X/17/3518w-1982w/\$20.00

\section{Genomic Classifier Augments the Role of Pathological Features in Identifying Optimal Candidates for Adjuvant Radiation Therapy in Patients With Prostate Cancer: Development and Internal Validation of a Multivariable Prognostic Model}

Deepansh Dalela, María Santiago-Jiménez, Kasra Yousefi, R. Jeffrey Karnes, Ashley E. Ross, Robert B. Den, Stephen J. Freedland, Edward M. Schaeffer, Adam P. Dicker, Mani Menon, Alberto Briganti, Elai Davicioni, and Firas Abdollah

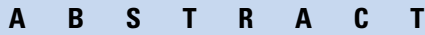

\section{Purpose}

Despite documented oncologic benefit, use of postoperative adjuvant radiotherapy (aRT) in patients with prostate cancer is still limited in the United States. We aimed to develop and internally validate a risk-stratification tool incorporating the Decipher score, along with routinely available clinicopathologic features, to identify patients who would benefit the most from aRT.

\section{Patient and Methods}

Our cohort included 512 patients with prostate cancer treated with radical prostatectomy at one of four US academic centers between 1990 and 2010. All patients had $\geq$ pT3a disease, positive surgical margins, and/or pathologic lymph node invasion. Multivariable Cox regression analysis tested the relationship between available predictors (including Decipher score) and clinical recurrence (CR), which were then used to develop a novel risk-stratification tool. Our study adhered to the Transparent Reporting of a Multivariable Prediction Model for Individual Prognosis or Diagnosis guidelines for development of prognostic models.

\section{Results}

Overall, $21.9 \%$ of patients received aRT. Median follow-up in censored patients was 8.3 years. The 10 -year CR rate was $4.9 \%$ vs. $17.4 \%$ in patients treated with aRT versus initial observation $(P<.001)$. Pathologic T3b/T4 stage, Gleason score 8-10, lymph node invasion, and Decipher score $>0.6$ were independent predictors of $\mathrm{CR}$ (all $P<.01$ ). The cumulative number of risk factors was $0,1,2$, and 3 to 4 in $46.5 \%, 28.9 \%, 17.2 \%$, and $7.4 \%$ of patients, respectively. aRT was associated with decreased CR rate in patients with two or more risk factors (10-year CR rate $10.1 \%$ in aRT $v 42.1 \%$ in initial observation; $P=.012)$, but not in those with fewer than two risk factors $(P=.18)$.

\section{Conclusion}

Using the new model to indicate aRT might reduce overtreatment, decrease unnecessary adverse effects, and reduce risk of CR in the subset of patients (approximately $25 \%$ of all patients with aggressive pathologic disease in our cohort) who benefit from this therapy.

\section{J Clin Oncol 35:1982-1990. (c) 2017 by American Society of Clinical Oncology}

\section{INTRODUCTION}

Prostate cancer (PCa) is the most common noncutaneous malignancy and the second most common cause of cancer-specific mortality in North American men. Despite widespread prostate-specific antigen (PSA) screening and the consequent stage migration, ${ }^{1}$ up to $40 \%$ of contemporary men undergoing radical prostatectomy (RP) may harbor aggressive disease at pathology, 2,3 These men are at the highest risk of recurrence and would benefit from postoperative radiation therapy (RT) with or without androgen deprivation therapy (ADT). ${ }^{4}$

Three randomized clinical trials from North America and Europe showed better oncologic outcomes in men treated with adjuvant RT (aRT) when harboring adverse pathologic characteristics at surgery. ${ }^{5-7}$ However, the use of aRT in contemporary American patients remains limited 
at best (approximately $10 \%$ to $12 \%$ ). ${ }^{8,9}$ This might be due to the concern of overtreatment, because up to $40 \%$ of patients in the control arms of these trials remained disease free. ${ }^{5-7}$ Moreover, the beneficial impact of aRT on oncologic outcomes is accompanied by an important risk of compromising functional outcomes after surgery. ${ }^{10}$ As such, there is a critical need to identify patients who are most likely to accrue curative benefit from aRT. In this context, genomic tests such as the Decipher (GenomeDx Biosciences, Vancouver, British Columbia, Canada) have recently shown promising results in prognosticating 5- and 10-year metastases rates after $\mathrm{RP},{ }^{11-18}$ with Den et $\mathrm{al}^{13}$ reporting on the ability of the Decipher score to potentially identify men likely to benefit from adjuvant versus salvage RT. However, comparative outcomes for men who did not develop biochemical recurrence or received aRT after surgery (which might be the case in a substantial proportion of men with aggressive disease $\mathrm{e}^{5-7}$ ) were not reported in the Den et $\mathrm{al}^{13}$ study. Additionally, although the reported outcomes were stratified based on Decipher score $(<0.4 v \geq 0.4)$, ${ }^{13}$ pathologic tumor characteristics were not taken into account. The number and nature of these characteristics are considered a good indicator of who would benefit from aRT. ${ }^{19}$

To address these limitations, we combined genomic data (ie, the Decipher score) and pathologic tumor characteristics to identify patients who would derive the most oncologic benefit from aRT versus initial observation (with or without subsequent salvage RT). We adhered to the Transparent Reporting of a Multivariable
Prediction Model for Individual Prognosis or Diagnosis (TRIPOD) guidelines for development and internal validation of a prognostic model during the conduct of the study. ${ }^{20}$

\section{PATIENTS AND METHODS}

\section{Patient Cohort}

We focused on a total of 512 patients with PCa treated with RP between 1990 and 2010 at one of four academic institutions: Mayo Clinic $(\mathrm{n}=141)$, Durham Veterans Affairs $(\mathrm{n}=104)$, Johns Hopkins Medical Institution $(\mathrm{n}=141)$, and Thomas Jefferson University $(\mathrm{n}=126) .{ }^{12,15,17,21}$ All patients had at least one adverse pathologic feature at the time of surgery (ie, $\geq$ pT3a stage, positive surgical margins [PSMs], and/or lymph node invasion [LNI]) and reached undetectable PSA levels after surgery. Postoperatively, these individuals received either aRT or initial observation (with salvage RT [sRT] offered in case of biochemical recurrence).

Details of inclusion and exclusion criteria are reported in Figure 1. Patient tumors (ie, RP specimens) were collected under institutional review board-approved studies of the Decipher test and data were stored in the GenomeDx PCa Genomic Resource Information Database.

\section{Specimen Collection and Handling}

Specimen selection and processing has been described in detail. ${ }^{14}$ Briefly, after microarray quality control using the Affymetrix Power Tools packages (Thermo Fisher Scientific, Waltham, MA), ${ }^{22}$ probe set summarization and normalization were performed using the single-channel array-normalization algorithm. ${ }^{23}$ None of these samples were used in the

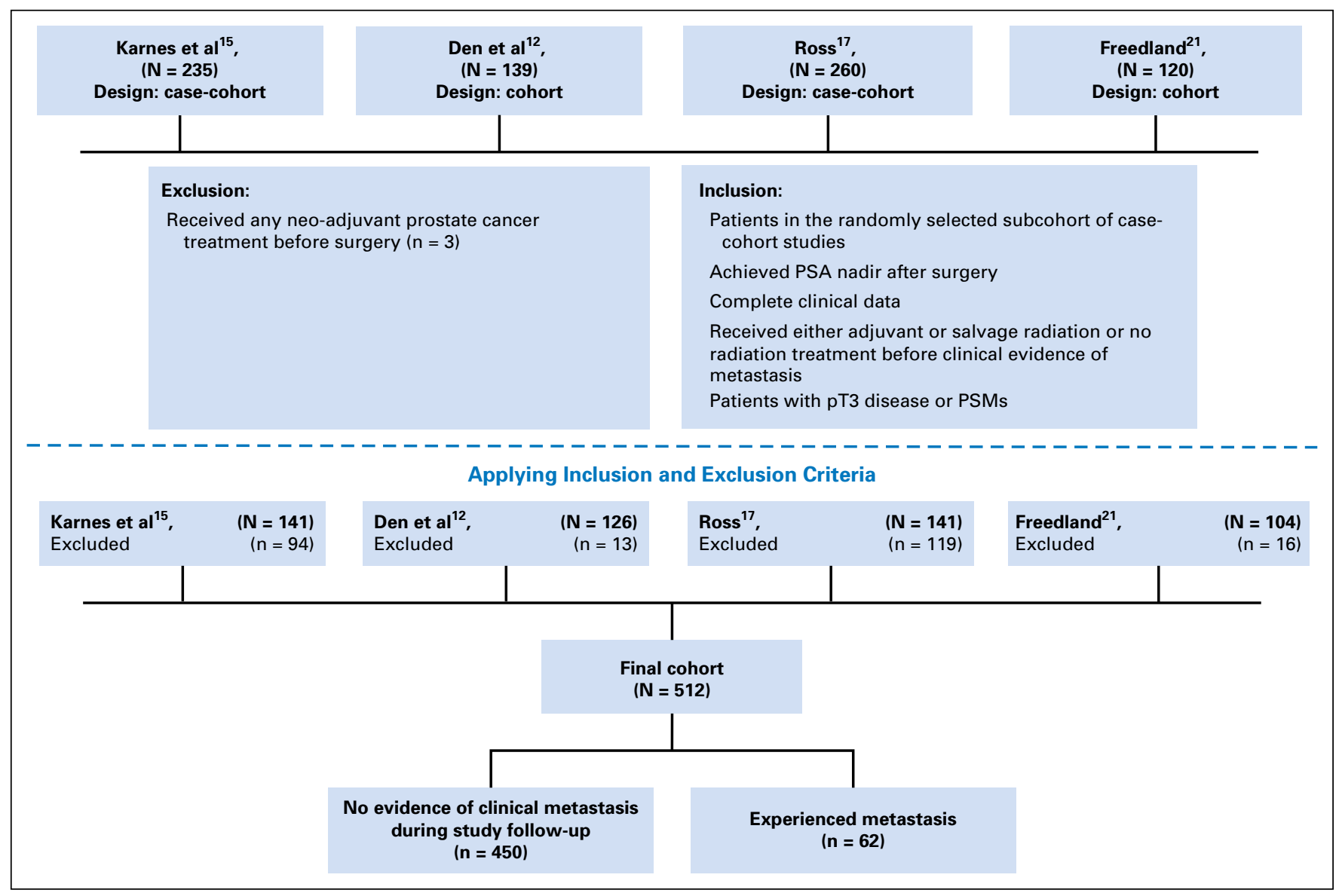

Fig 1. Flow diagram illustrating the study cohort selection. PSA, prostate-specific antigen; PSM, positive surgical margin. 
development of the Decipher genomic classifier. The study adheres to the Reporting Recommendations for Tumor Marker Prognostic Studies criteria for evaluation of prognostic biomarkers. ${ }^{24}$

\section{Calculation of Genomic Risk of Metastasis}

Genomic risk of metastasis was calculated with the Decipher test, which has been validated as an independent predictor of clinical metastatic progression after RP in different studies across multiple cohorts. ${ }^{1-18}$ The Decipher score was calculated from RP specimens. The expression values for the 22 prespecified biomarkers that constitute Decipher were extracted from the normalized data matrix and entered into the locked random forest algorithm with tuning and weighting parameters defined as reported previously. ${ }^{13,14}$ The Decipher read-out is a continuous risk score between 0 and 1 , with higher scores indicating a greater probability of metastasis at 5 and 10 years after RP. ${ }^{14,16,17}$ The Decipher score was also categorized into low, intermediate, and high risk $(<0.45,0.45$ to 0.6 , and $>0.6$, respectively) based on previously reported methodology. ${ }^{17,21}$

\section{Clinicopathologic Variables}

Key preoperative variables of interest were age (in years) at RP and preoperative PSA level; postoperatively, the pathologic variables included pathologic Gleason score, stage, PSM status, and LNI status. aRT was defined as receiving radiotherapy within 12 months from RP, with postoperative PSA levels of $<0.2 \mathrm{ng} / \mathrm{mL}$. Similar conditions were used to identify adjuvant ADT. Patients who did not receive any adjuvant treatment after surgery were categorized as the initial observation group. Salvage treatments were identified as receiving RT and/or ADT after documented biochemical recurrence (PSA levels $\geq 0.2 \mathrm{ng} / \mathrm{mL}$ confirmed on two separate occasions), or RT and/or ADT administered $\geq 12$ months after RP.

\section{Outcome Definition}

The primary end point of the study was time to clinical recurrence (CR; as documented from prostatic fossa biopsy specimen, and/or radiographically on computed tomography scan, bone scan, and/or other imaging modalities). Follow-up time was calculated from time of surgery to time of CR, or time of last available contact. Patients who died before CR were considered to be censored. Of note, GenomeDx Biosciences staff and personnel were blinded to the CR status during the laboratory processing and calculation of Decipher for all patients in the study.

\section{Statistical Analyses}

Frequencies and proportions were reported for categorical variables, whereas median and interquartile ranges (IQRs) were reported for continuous variables. Differences in categorical and continuous variables were examined using the Fisher exact test and analysis of variance $\mathrm{F}$ test, respectively. The median follow-up time was reported only for censored patients ${ }^{25}$ and was determined by considering time of surgery and time to last available contact. The Gray test was used to compare cumulative incidence curves. $^{26}$

Our statistical analyses consisted of two main steps. First, univariable and multivariable Cox proportional hazards models were used to test the relationship between pathologic features/genomic feature (namely, the Decipher score) and CR after surgery. The predictors for the models were chosen a priori to performing the analyses. To account for the small number of events, the results of the multivariable models were confirmed using the Firth penalized likelihood method, ${ }^{27}$ which showed no substantive change in hazard ratios or $P$ values, and ensured robustness of the analyses. The coefficients of independent predictors from the multivariable model were used to develop a novel nomogram predicting individual probabilities of CR-free survival 5 and 10 years after RP. The discriminant accuracy of the novel nomogram was quantified using time-dependent concordance index (constructed using the nearest neighbor estimator with a span parameter of 0.001 as described by Heagerty et $\mathrm{al}^{28}$ ) and adjusted for optimism using bootstrapping with 1,000 resamples. Calibration plots assessed the overall extent of over- or underestimation of CR rates compared with nomogram-predicted probability of CR, and calibration was tested using the D'Agostino-Nam ${ }^{29}$ version of the Hosmer-Lemeshow test for survival data obtained from bootstrapped resamples.

Second, all independent predictors of CR from the aforementioned multivariable model were assigned a score of 1 and summed to generate a novel risk score. Next, cumulative incidence curves, stratified according to the novel risk score, were used to depict CR-rate estimates in men treated with aRT versus initial observation after surgery. Estimation of the number needed to treat (NNT) to prevent one episode of CR was calculated using the method described by Altman and Anderson. ${ }^{30}$

The accompanying checklist highlights the adherence to the TRIPOD statement guidelines (Appendix Table A1, online only). All statistical tests were two-sided and analyses were performed in $\mathrm{R}$ version 3.1 (R Foundation, Vienna, Austria).

\section{RESULTS}

Overall, median age (IQR) was 61 years ( 57 to 65 years). Pathologic Gleason score was $\geq 4+3$ in $48.4 \%$ of patients, and the majority $(72.3 \%)$ harbored extraprostatic disease (Table 1). Only 112 (21.9\%) of patients received aRT. These men harbored PSMs more frequently $(85.7 \% v 62.0 \%)$ and were less likely to have LNI $(0.9 \%$ $v 10.8 \%)$ compared with men managed with initial observation (both $P<.001$ ). In the initial observation group, 168 patients $(42 \%)$ in the initial observation group received sRT at a median (IQR) preradiotherapy PSA level of $0.55 \mathrm{ng} / \mathrm{mL}(0.33$ to $1.40 \mathrm{ng} /$ $\mathrm{mL}$ ). The median (IQR) time from RP to sRT was 11.1 months (4.9 to 30.8 months).

Overall, 62 patients (12.1\%) had documented CR through the study period. Median (IQR) follow-up among those who did not experience CR during the study period was 8.3 years (5.4 to 11.3 years). The 10 -year cumulative incidence of CR was $4.9 \%$ (95\% CI, $0.0 \%$ to $9.6 \%$ ) in aRT patients versus $17.4 \%$ (95\% CI, $12.7 \%$ to $21.9 \%)$ in initial observation patients $(P<.001)$. In multivariable analysis, pathologic pT3b/T4 disease (hazard ratio [HR], 3.63), pathologic Gleason score 8 to 10 (HR, 3.36), presence of LNI (HR, 2.26), and high ( $v$ low) Decipher score (HR, 2.93) were all independent predictors of higher risk of CR (all $P \leq .02$; Table 2). Of note, patients treated with aRT had a $66 \%$ lower CR risk than their counterparts treated with initial observation (HR, 0.34; 95\% CI, 0.11 to $0.82 ; P=.01)$. The coefficients of these independent predictors were used to develop a novel nomogram stratified by aRT status (Fig 2). Noteworthy, the Decipher score was used as a continuous variable in the nomogram (HR, 1.25 [95\% CI, 1.09 to 1.44]; $P=.002$; Appendix Table A2, online only). The discrimination accuracy of the novel nomogram for predicting 5-year CR risk was $85 \%$ ( $v 79 \%$ for the clinicopathologic model only, although the $95 \%$ CI of the C indices for the two models overlapped) and its calibration characteristics were favorable (HosmerLemeshow $P=.1$; Appendix Fig A1, online only).

In addition to the nomogram, a simple risk score was calculated for all patients in our cohort on the basis of multivariable analysis results. Specifically, the novel risk score represented the cumulative number of independent predictors of CR found in each patient (ie, pT3b/T4, pathologic Gleason score 8 to 10, LNI, and high Decipher score). The risk score was $0,1,2$, and 3 to 4 in 238 (46.5\%), $148(28.9 \%), 88(17.2 \%)$, and $38(7.4 \%)$ of patients, 
Table 1. Descriptive Statistics of Patients With Prostate Cancer Treated With Radical Prostatectomy at One of Four Academic Centers in the United States Between 1990 and $2010(\mathrm{~N}=512)^{*}$

\begin{tabular}{|c|c|c|c|c|}
\hline Variable & All Patients ( $N=512)$ & $\begin{array}{l}\text { No aRT or Initial Observation } \\
\qquad(\mathrm{n}=400 ; 78.1 \%)\end{array}$ & $\mathrm{aRT}(\mathrm{n}=112 ; 21.9 \%)$ & $P$ \\
\hline $\begin{array}{l}\text { Age at RP (years); median (IQR) } \\
\text { Range }\end{array}$ & $\begin{array}{r}61 \text { (57 to } 65) \\
\text { (38 to } 78)\end{array}$ & $\begin{array}{r}61 \text { (57 to } 65) \\
\text { (38 to } 78)\end{array}$ & $\begin{array}{r}60(57 \text { to } 64) \\
\text { (43 to } 78)\end{array}$ & .64 \\
\hline $\begin{array}{l}\text { Preoperative PSA level (ng/mL); median (IQR) } \\
\text { Range }\end{array}$ & $\begin{array}{l}8.1 \text { (5.5 to } 12.7) \\
\text { (0.4 to } 194.0)\end{array}$ & $\begin{array}{l}8.4(5.5 \text { to } 13.4) \\
\quad(0.4 \text { to } 194.0)\end{array}$ & $\begin{array}{r}7.3(5.3 \text { to } 10.8) \\
(1.3 \text { to } 45.1)\end{array}$ & .04 \\
\hline $\begin{array}{l}\text { Gleason grade } \\
\begin{array}{l}3+3 \\
3+4 \\
4+3 \\
8 \\
9-10\end{array}\end{array}$ & $\begin{aligned} 41 & (8.0) \\
221 & (43.2) \\
112 & (21.9) \\
57 & (11.1) \\
79 & (15.4)\end{aligned}$ & $\begin{aligned} 30 & (7.5) \\
176 & (44.0) \\
87 & (21.8) \\
42 & (10.5) \\
65 & (16.2)\end{aligned}$ & $\begin{array}{l}11(9.8) \\
45(40.2) \\
25(22.3) \\
15(13.4) \\
14(12.5)\end{array}$ & .65 \\
\hline $\begin{array}{l}\text { Pathologic stage } \\
\text { pT2 } \\
\text { pT3a } \\
\text { pT3b } \\
\text { pT4 }\end{array}$ & $\begin{array}{c}142(27.7) \\
201(39.3) \\
145(28.3) \\
24(4.7)\end{array}$ & $\begin{array}{l}104(26.0) \\
164(41.0) \\
112(28.0) \\
20(5.0)\end{array}$ & $\begin{array}{l}38(33.9) \\
37(33.0) \\
33(29.5) \\
4(3.6)\end{array}$ & .18 \\
\hline $\begin{array}{l}\text { Positive surgical margin } \\
\text { Lymph node invasion } \\
\text { Adjuvant ADT } \\
\text { Median Decipher GC risk score (IOR) } \\
\text { Range }\end{array}$ & $\begin{array}{l}344(67.2) \\
44(8.6) \\
76(14.8) \\
0.41(0.26 \text { to } 0.56) \\
0.00 \text { to } 0.96\end{array}$ & $\begin{array}{l}248(62.0) \\
43(10.8) \\
60(15.0) \\
0.41(0.25 \text { to } 0.56) \\
0.00 \text { to } 0.96\end{array}$ & $\begin{aligned} & 96(85.7) \\
& 1(0.9) \\
& 16(14.3) \\
& 0.41(0.26 \text { to } 0.54) \\
& 0.04 \text { to } 0.81\end{aligned}$ & $\begin{array}{c}<.001 \\
<.001 \\
1 \\
.9\end{array}$ \\
\hline $\begin{array}{l}\text { Decipher GC risk category } \\
\text { Low } \\
\text { Intermediate } \\
\text { High }\end{array}$ & $\begin{array}{r}285(55.7) \\
134(26.2) \\
93(18.2)\end{array}$ & $\begin{array}{r}223(55.8) \\
103(25.8) \\
74(18.5)\end{array}$ & $\begin{array}{l}62(55.4) \\
31(27.7) \\
19(17.0)\end{array}$ & .9 \\
\hline $\begin{array}{l}\text { Follow-up time in censored patients, } \\
\text { median (IQR) (years) } \\
\text { Range }\end{array}$ & $\begin{array}{l}8.2(5.4 \text { to } 11.3) \\
0.2 \text { to } 19.2\end{array}$ & $\begin{array}{l}8.5 \text { (5.4 to } 11.3) \\
0.2 \text { to } 19.2\end{array}$ & $\begin{array}{l}7.7(5.4 \text { to } 10.8) \\
0.5 \text { to } 16.2\end{array}$ & .08 \\
\hline $\begin{array}{l}\text { sRT } \\
\quad \text { Early sRT }(P S A \leq 0.5 \mathrm{ng} / \mathrm{mL}) \\
\quad \text { Late } \mathrm{sRT}(\mathrm{PSA}>0.5 \mathrm{ng} / \mathrm{mL})\end{array}$ & $168(32.8)$ & $\begin{array}{r}168(42.0) \\
80(47.6) \\
88(52.4)\end{array}$ & $0(0.0)$ & \\
\hline $\begin{array}{l}\text { Time from RP to RT, median (IQR) (years) } \\
\text { Range }\end{array}$ & & $\begin{array}{l}11.1(4.9 \text { to } 30.8) \\
1.3 \text { to } 159.7\end{array}$ & $\begin{array}{l}4.8(3.7 \text { to } 10.6) \\
1.1 \text { to } 142.3\end{array}$ & $<.001$ \\
\hline $\begin{array}{l}\text { Pre-RT PSA, median (IQR) (ng/mL) } \\
\text { Range }\end{array}$ & & $\begin{array}{l}0.55(0.33 \text { to } 1.40) \\
0.20 \text { to } 49.40\end{array}$ & $\begin{array}{c}0.10(0.05 \text { to } 0.10) \\
0.0 \text { to } 0.19\end{array}$ & $<.001$ \\
\hline
\end{tabular}

NOTE: Data given as No. (\%) or median (IQR), unless otherwise indicated.

Abbreviations: ADT, androgen deprivation therapy; GC, genomic classifier; IQR, interquartile range; PSA, prostate specific antigen; RP, radical prostatectomy; sRT, salvage radiotherapy.

${ }^{*}$ All patients had adverse pathologic features at surgery. Patients were stratified based on adjuvant radiotherapy status

respectively. Figure 3 shows the cumulative incidence of CR in our cohort after stratifying patients according to the novel risk score. At 10 years, the CR rate was $5.6 \%, 12.4 \%, 27.3 \%$, and $57.4 \%$ in patients with risk scores of $0,1,2$, and 3 to 4 , respectively $(P<.001)$. In patients treated with aRT versus initial observation, the 10 -year CR rate was $3.5 \%$ versus $9.3 \%$ in patients with a risk

Table 2. Cox Regression Analysis Predicting Clinical Recurrence in Patients With Prostate Cancer With Adverse Pathologic Features After Radical Prostatectomy $(\mathrm{N}=512)$

\begin{tabular}{|c|c|c|c|c|}
\hline \multirow[b]{2}{*}{ Variable } & \multicolumn{2}{|c|}{ Univariate Model } & \multicolumn{2}{|c|}{ Multivariate Model } \\
\hline & $\mathrm{HR}(95 \% \mathrm{Cl})$ & $P$ & $\mathrm{HR}(95 \% \mathrm{Cl})$ & $P$ \\
\hline Preoperative PSA (Log2) & 1.27 (0.99 to 1.61$)$ & .06 & 1.25 (0.97 to 1.59$)$ & .08 \\
\hline \multicolumn{5}{|l|}{ Pathologic stage } \\
\hline рT3a ( $v$ pT2) & 2.63 (1.11 to 7.45$)$ & .03 & $2.47(0.94$ to 8.05$)$ & .07 \\
\hline $\mathrm{pT} 3 \mathrm{~b} / \mathrm{pT} 4(v \mathrm{pT} 2)$ & 5.97 (2.64 to 16.5$)$ & $<.001$ & $3.63(1.38$ to 11.86$)$ & .008 \\
\hline Pathologic Gleason score (8-10 $v \leq 7)$ & 5.07 (3.07 to 8.53$)$ & $<.001$ & $3.36(1.96$ to 5.85$)$ & $<.001$ \\
\hline Lymph node invasion & 4.49 (2.48 to 7.72$)$ & $<.001$ & $2.26(1.14$ to 4.31$)$ & .02 \\
\hline Surgical margins & 0.97 (0.58 to 1.66$)$ & .9 & 1.59 (0.93 to 2.78$)$ & .09 \\
\hline Adjuvant radiotherapy & $0.29(0.10$ to 0.68$)$ & .003 & $0.34(0.11$ to 0.82$)$ & .01 \\
\hline Adjuvant hormonal therapy & $1.75(0.9$ to 3.17$)$ & .1 & $0.64(0.31$ to 1.26$)$ & .2 \\
\hline Decipher intermediate risk ( $v$ low) & 1.8 (0.93 to 3.44$)$ & .08 & $1.40(0.70$ to 2.74$)$ & .34 \\
\hline Decipher high risk ( $v$ low) & 4.62 (2.6 to 8.33 ) & $<.001$ & 2.93 (1.58 to 5.55$)$ & $<.001$ \\
\hline
\end{tabular}

NOTE. All patients were treated between 1990 and 2010 at one of four US academic centers.

Abbreviations: HR, hazard ratio; PSA, prostate-specific antigen. 


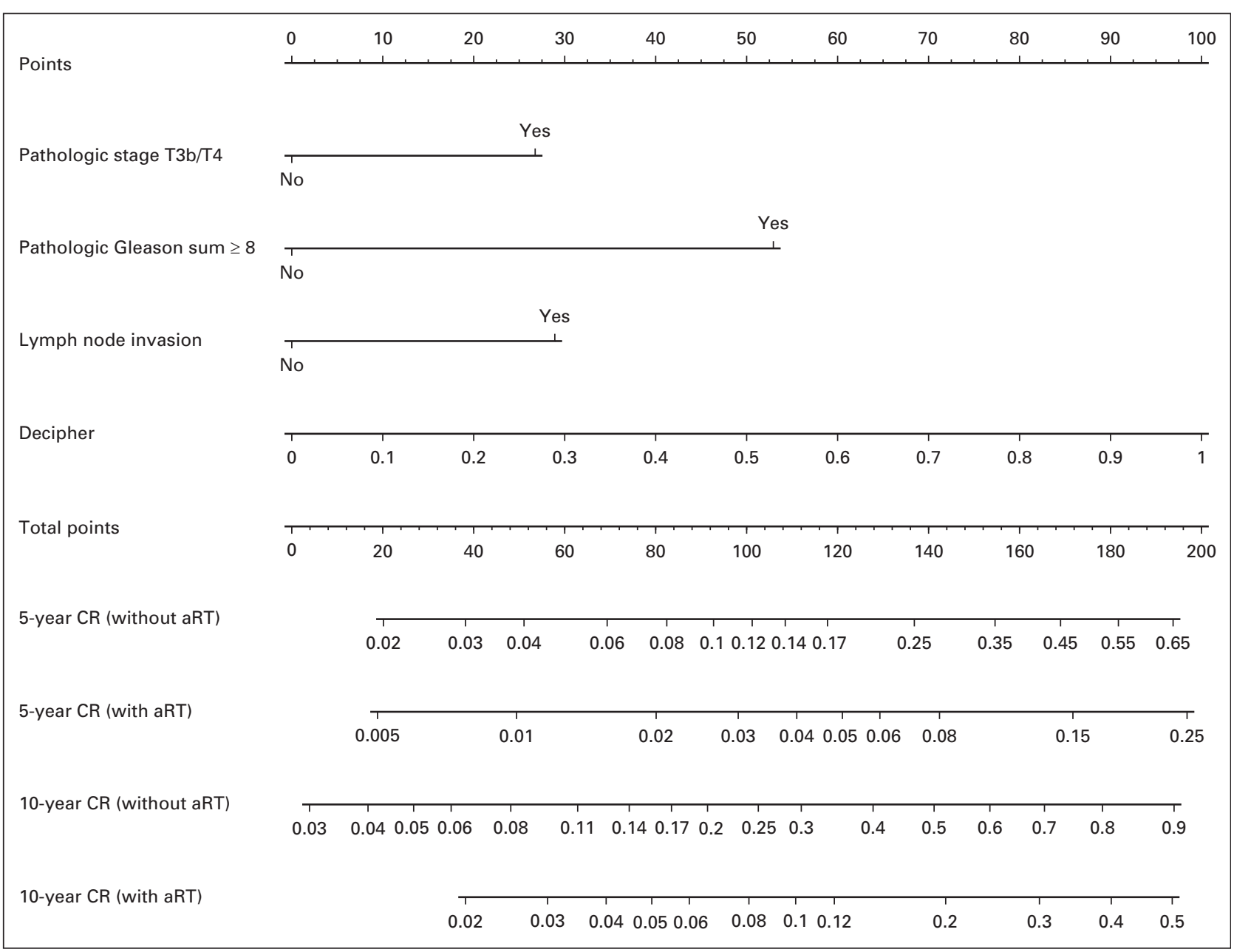

Fig 2. Nomogram predicting the probability of clinical recurrence-free survival (CRFS) in patients with prostate cancer with adverse pathologic features at radical prostatectomy on the basis of pathologic stage, pathologic Gleason score, lymph node invasion, and Decipher score. Nomogram outcomes were stratified based on adjuvant radiotherapy (aRT) status. For example, locate the patient's Decipher score on the Decipher axis. Draw a line straight up to the point axis to determine how many points toward the probability of CRFS the patient receives for his Decipher score. Repeat the process for each additional variable. Sum the points for each predictor. Locate the final sum on the total-point axis. Draw a line straight down to find the patient's 5- and 10-year probability of CRFS. CR, clinical recurrence.

score $<2(P=.18$; Fig $4 \mathrm{~A})$, and $10.1 \%$ versus $42.1 \%$ in patients with a risk score $\geq 2(P=.012$; Fig $4 \mathrm{~B})$. At 10 years, NNT to prevent one CR was 3.1 (95\% CI, 2.9 to 3.3) in patients with risk score $\geq 2$.

Last, given that only one patient with LNI received aRT in our cohort, we conducted post hoc sensitivity analyses after excluding all men with LNI (Appendix). Independent risk factors for CR were pathologic stage pT3b/T4 (HR, 2.65,), pathologic Gleason score 8 to 10 ( $\mathrm{HR}, 3.85)$, and high Decipher score (HR, 2.90; all $P \leq .04)$. For patients treated with aRT versus initial observation, the 10 -year CR rate was $3.5 \%$ versus $9.6 \%$ in patients with a risk score $<2$ $(P=.21)$, and $10.6 \%$ versus $37.2 \%$ in patients with a risk score $\geq 2$ $(P=.04)$.

\section{DISCUSSION}

Despite level I evidence data demonstrating the favorable impact of aRT on cancer control outcomes in patients with PCa with adverse pathologic characteristics at surgery, ${ }^{5-7}$ the use of this treatment modality is still very limited across the United States (approximately $10 \%$ to $12 \%) .{ }^{8,9}$ This might be attributed to many reasons, such as concerns about overtreatment, radiation toxicity, ${ }^{5-7}$ adverse impact of radiation on post-RP functional outcomes, ${ }^{10}$ and patient preferences. $^{31}$ As a result, many physicians prefer an approach of initial observation with or without sRT at biochemical recurrence. However, the efficacy of the latter treatment modality has not been demonstrated. One approach to overcome this clinical dilemma might be a better definition of patients who actually need aRT. In this study, we combined genomic data (ie, the Decipher risk score) and histopathology data to identify the optimal candidate for aRT after surgery among patients with PCa with adverse pathologic characteristics. ${ }^{8,9}$

Our analyses showed several important findings. First, we demonstrate that incorporating Decipher added incremental prognostic value in identifying patients with adverse pathologic features (ie, extraprostatic disease, pathologic Gleason score 8 to 10 , or presence of LNI) at a higher risk of CR after RP, with a predictive accuracy of $85 \%$. Based on the combined clinicopathologic and genomic parameters, we created a novel nomogram to quantify the likelihood of CR-free survival 5 and 10 years after 




Fig 3. Cumulative incidence plot depicting clinical recurrence (CR) curves of 512 patients with prostate cancer with adverse pathologic features at radical prostatectomy (RP). Patients were stratified based on the risk score described in this study. All patients were treated at one of four academic centers in the United States between 1990 and 2010. $P$ value was calculated using Gray test.

RP (stratified by receipt of aRT), which showed optimal discrimination and calibration characteristics. Whereas prior studies have combined Decipher with pre-existing validated models (such as the postsurgical Cancer of the Prostate Risk Assessment [CAPRA-S] or the Stephenson nomogram), ${ }^{11,13}$ our study attempted to incorporate genomic features with routinely available clinicopathologic parameters to create a de novo prediction model. This was then used to derive an easily used risk score. Importantly, every one-point increment in the risk score was associated with a doubling of CR risk at 10 years post-RP. Of note, this study is based on genomic parameters that adhere to the recently published TRIPOD guidelines for developing and reporting prognostic models. $^{20}$ Adherence to the guidelines increases the methodological strengths of our study and allows readers to transparently assess the risk of bias and potential usefulness in a given clinical setting. Our work represents a type $1 \mathrm{~b}$ study per the TRIPOD statement (corresponding to development and internal validation) and lays the foundation for future external validation studies.
Second, our results provide vital information to guide decision making regarding aRT in patients with aggressive pathology. aRT use did not substantially alter the nomogram-predicted CRfree survival in patients with few pathologic risk factors and low Decipher score (ie, risk score $<2$ ), allowing a substantial proportion of patients to safely omit unnecessary aRT. Conversely, those with more aggressive disease and higher Decipher scores (ie, risk score $\geq 2$ ) demonstrated greater benefit with upfront aRT versus initial observation. Indeed, for patients in the latter group at 5 and 10 years post-RP, the absolute reduction in risk of CR was $17.3 \%$ and $32.0 \%$, respectively (corresponding to a relative risk reduction of $63 \%$ and $76 \%$, respectively). At 10 years, the NNT to prevent one $\mathrm{CR}$ in patients with risk score $\geq 2$ was 3.1 ; the corresponding NNT on the basis of current recommendations (derived from the European Organization for Research and Treatment of Cancer trial 22911 and the Southwest Oncology Group 8794 trials) would be approximately 10. Although the riskscoring system has practical use in a busy clinical setting for patient 


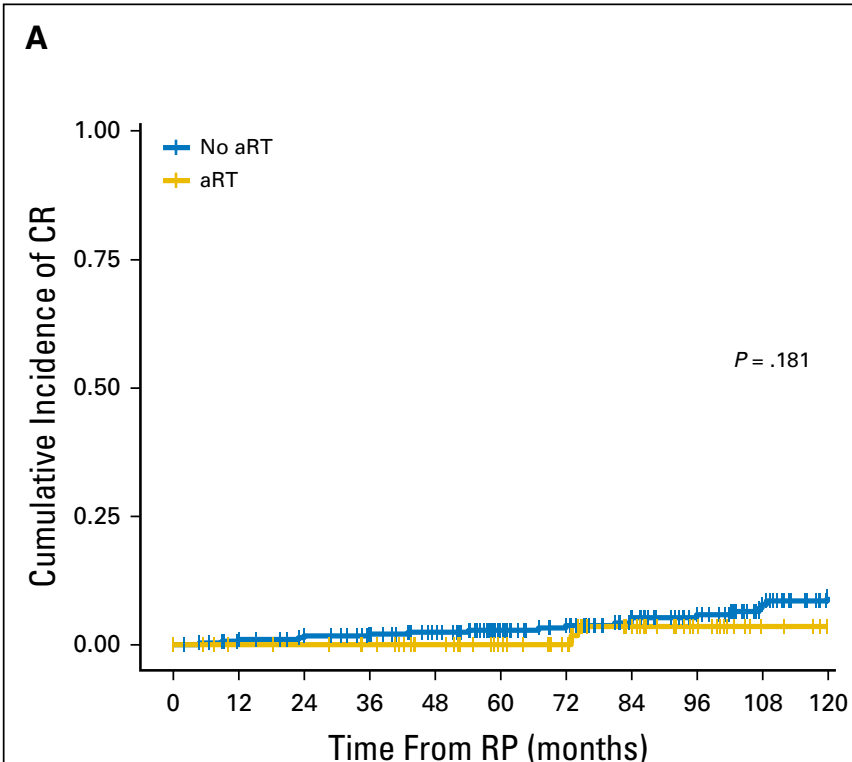

No. at risk

$\begin{array}{rccccccccccc}\text { aRT } & 89 & 86 & 85 & 82 & 75 & 67 & 60 & 49 & 37 & 27 & 23 \\ \text { No aRT } & 297 & 291 & 286 & 276 & 264 & 241 & 211 & 186 & 164 & 137 & 114\end{array}$

\begin{tabular}{|c|c|c|c|c|}
\hline \multirow{2}{*}{$\begin{array}{c}\text { Treatment } \\
\text { Arm }\end{array}$} & No. (\%) & $\begin{array}{c}\text { Follow-Up of Censored } \\
\text { Patients, median } \\
\text { (O1 to Q3) (years) }\end{array}$ & \multicolumn{2}{|c|}{ Clinical Recurrence Rate (95\% CI) } \\
\cline { 4 - 6 } & & $\mathbf{6 0}$ Months & $\mathbf{1 2 0}$ Months \\
\hline aRT & $89(23)$ & $7.4(5$ to 10.1$)$ & $0.0(0.0$ to 0.0$)$ & $3.5(0.0$ to 8.2$)$ \\
\hline No aRT & $297(77)$ & $8.7(5.2$ to 11.4$)$ & $2.8(0.9$ to 4.7$)$ & $9.3(5.0$ to 13.4$)$ \\
\hline
\end{tabular}

B

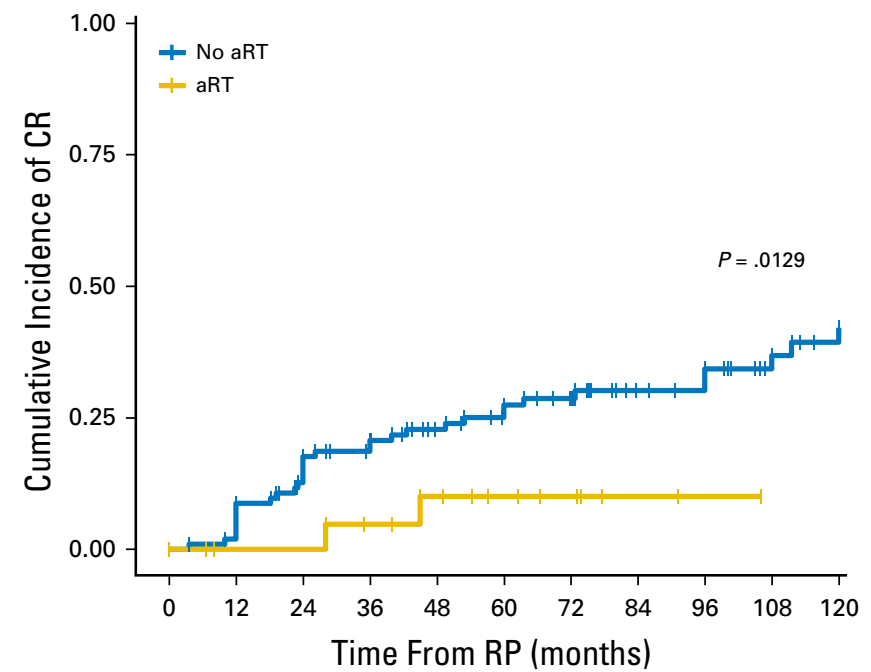

No. at risk

$\begin{array}{llllllllllll}\text { aRT } & 23 & 21 & 21 & 19 & 17 & 14 & 12 & 9 & 8 & 7 & 7\end{array}$ $\begin{array}{llllllllllll}\text { No aRT } & 103 & 101 & 88 & 79 & 69 & 63 & 55 & 36 & 34 & 26 & 22\end{array}$

\begin{tabular}{|c|c|c|c|c|}
\hline \multirow{2}{*}{$\begin{array}{c}\text { Treatment } \\
\text { Arm }\end{array}$} & \multirow{2}{*}{ No. (\%) } & \multirow{2}{*}{$\begin{array}{c}\text { Follow-Up of Censored } \\
\text { Patients, median } \\
\text { (Q1 to Q3) (years) }\end{array}$} & \multicolumn{2}{|c|}{ Clinical Recurrence Rate (95\% CI) } \\
\cline { 4 - 5 } & & $\mathbf{6 0}$ Months & $\mathbf{1 2 0}$ Months \\
\hline aRT & $23(18)$ & $6.1(3.9$ to 12.2$)$ & $10.1(0.0$ to 22.4$)$ & $10.1(0.0$ to 22.4$)$ \\
\hline No aRT & $103(82)$ & $6.0(3.0$ to 8.9$)$ & $27.4(18.0$ to 35.8$)$ & $42.1(28.3$ to 53.2) \\
\hline
\end{tabular}

Fig 4. Cumulative incidence plot depicting clinical recurrence (CR) curves in patients with prostate cancer with adverse pathologic features at radical prostatectomy (RP).

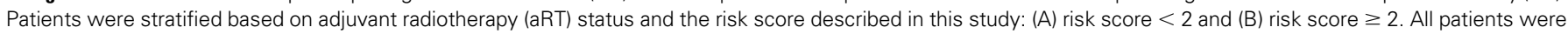
treated at one of four academic centers in the United States between 1990 and 2010. $P$ value was calculated using Gray test.

counseling regarding the need for aRT, our nomogram can provide individualized estimation of CR risk (both at 5 and 10 years post-RP) in men who opt for aRT and those preferring an initial observation approach. Given the fairly protracted natural history of PCa, 10-year CR estimates may arguably provide greater clinical use to Decipher-based models. This, in turn, may enhance shared decision making between urologists and their patients. Pending the results of the RADICALS (Radiotherapy and Androgen Deprivation in Combination after Local Surgery), ${ }^{32}$ GETUG-17/0702 ${ }^{33}$ and RAVES (Radiotherapy-Adjuvant Versus Early Salvage) ${ }^{34}$ trials comparing aRT with initial observation with or without salvage RT, our results suggest it might not be prudent to withhold aRT in favor of an initial observation approach patients with risk score $\geq 2$.

Last, our results corroborate the findings reported by Den et $\mathrm{al},{ }^{13}$ who suggested that aRT may offer significantly greater CRfree survival than salvage RT in men with high Decipher score $(\geq 0.4)$, but not in men with lower Decipher scores. Nonetheless, there are key differences as well. Most importantly, the control group (ie, sRT) in the Den et $\mathrm{al}^{13}$ study excluded men treated with initial observation: Given that $35 \%$ to $40 \%$ of patients treated with initial observation may not experience a biochemical recurrence ${ }^{5,7}$ within 10 years of RP (thereby obviating the need for salvage therapy), inclusion of such patients is necessary in deriving conclusions regarding the oncologic efficacy for aRT. ${ }^{35}$ Of note, the median time to sRT was 11.1 months in our cohort (compared with 5 months in the Den et $\mathrm{al}^{13}$ study), more closely reflecting the natural history of an initial observation versus an upfront aRT approach in the post-RP setting. Next, the C index of the Decipheronly model in our study was somewhat lower compared with that reported by Den et al. ${ }^{13}$ As alluded to earlier, this could be due to different patient populations in the initial observation arm (with or without sRT), and although direct comparison of aRT with only salvage RT may improve the discrimination power from a statistical standpoint, it may not be truly reflective of a clinical setting. Finally, risk stratification of patients into those likely to benefit from upfront aRT versus those who may not was based solely on low versus intermediate/high Decipher score in the Den et al study. ${ }^{13}$ We have previously shown the prognostic role of histopathologic features (ie, pathologic stage, Gleason score, and presence of LNI) in predicting cancer-specific mortality in patients undergoing aRT. $^{19}$ As such, our current study shows that incorporating both Decipher and clinicopathologic feature results in a better accuracy when predicting CR after surgery.

Our study must be interpreted in light of its limitations. First, this retrospective study spanned patients diagnosed and treated over two decades (1990 to 2010); the widespread dissemination of PSA screening leading to downstaging of PCa, evolution of aRT or adjuvant ADT protocols, and modifications in the Gleason grading system over the study period may be meaningful confounders of 
results. These data originated at four high-volume academic centers and, as such, would require validation at the community level with both low- and high-volume facilities. The median RT dose was $66.6 \mathrm{~Gy}$, which, although somewhat lower by contemporary standards, is comparable to what has been reported in the three large-scale randomized controlled trials on aRT ( 60 to $64 \mathrm{~Gy}$ ). ${ }^{5-7}$ Second, although we accounted for the use of adjuvant ADT, its use was largely driven by surgeon and/ or institutional preferences. There continues to be a lack of consensus regarding the role of $\mathrm{ADT}$ in the adjuvant setting, ${ }^{36-38}$ and the role of aRT with or without ADT, especially in patients with pN1 disease, is currently a matter of investigation. ${ }^{39}$ Third, a central pathologic review was not undertaken; however, dedicated genitourinary pathologists at each center examined the histopathology specimens, which may reduce but not entirely eliminate the possibility of interobserver and/or misclassification bias. Fourth, we did not see a statistically significant association between PSM and CR rate: Although it is conceivable that relatively fewer patients precluded this finding, evidence regarding association of PSM with metastases-free survival is rather contradictory, even in level I studies. ${ }^{5-7}$

\section{AUTHORS' DISCLOSURES OF POTENTIAL CONFLICTS} OF INTEREST

Disclosures provided by the authors are available with this article at jco.org.

\section{AUTHOR CONTRIBUTIONS}

Conception and design: Kasra Yousefi, R. Jeffrey Karnes, Elai Davicioni, Firas Abdollah

Administrative support: R. Jeffrey Karnes, Mani Menon

Provision of study materials or patients: María Santiago-Jiménez,

Stephen J. Freedland, Mani Menon, Elai Davicioni

Collection and assembly of data: María Santiago-Jiménez, Kasra Yousefi, R. Jeffrey Karnes, Stephen J. Freedland

Data analysis and interpretation: Deepansh Dalela, Kasra Yousefi, R. Jeffrey Karnes, Ashley E. Ross, Robert B. Den, Stephen J. Freedland, Edward M. Schaeffer, Adam P. Dicker, Mani Menon, Alberto Briganti, Firas Abdollah

Manuscript writing: All authors

Final approval of manuscript: All authors

Accountable for all aspects of the work: All authors

\section{REFERENCES}

1. Shao YH, Demissie K, Shih W, et al: Contemporary risk profile of prostate cancer in the United States. J Natl Cancer Inst 101:1280-1283, 2009

2. Kalbasi $A$, Swisher-McClure $S$, Mitra $N$, et al: Low rates of adjuvant radiation in patients with nonmetastatic prostate cancer with high-risk pathologic features. Cancer 120:3089-3096, 2014

3. Silberstein JL, Vickers AJ, Power NE, et al: Reverse stage shift at a tertiary care center: Escalating risk in men undergoing radical prostatectomy. Cancer 117:4855-4860, 2011

4. Mohler JL, Armstrong AJ, Bahnson RR, et al: Prostate cancer, version 1.2016. J Natl Compr Canc Netw 14:19-30, 2016

5. Bolla M, van Poppel $H$, Tombal B, et al: Postoperative radiotherapy after radical prostatectomy for high-risk prostate cancer: Long-term results of a randomised controlled trial (EORTC trial 22911). Lancet 380:2018-2027, 2012

6. Thompson IM, Tangen CM, Paradelo J, et al: Adjuvant radiotherapy for pathological T3NOMO prostate cancer significantly reduces risk of metastases and improves survival: Long-term followup of a randomized clinical trial. J Urol 181:956-962, 2009

7. Wiegel T, Bartkowiak D, Bottke D, et al: Adjuvant radiotherapy versus wait-and-see after radical prostatectomy: 10-year follow-up of the ARO 96-02/ AUO AP 09/95 trial. Eur Urol 66:243-250, 2014

8. Mahal BA, Hoffman KE, Efstathiou JA, et al: National trends in the recommendation of radiotherapy after prostatectomy for prostate cancer before and after the reporting of a survival benefit in March 2009. Clin Genitourin Cancer 13:e167-e172, 2015

9. Sineshaw HM, Gray PJ, Efstathiou JA, et al: Declining use of radiotherapy for adverse features after radical prostatectomy: Results from the $\mathrm{Na}$ tional Cancer Data Base. Eur Urol 68:768-774, 2015

10. Suardi N, Gallina A, Lista G, et al: Impact of adjuvant radiation therapy on urinary continence recovery after radical prostatectomy. Eur Urol 65: 546-551, 2014

11. Cooperberg MR, Davicioni $E$, Crisan A, et al: Combined value of validated clinical and genomic risk stratification tools for predicting prostate cancer mortality in a high-risk prostatectomy cohort. Eur Urol 67:326-333, 2015

12. Den RB, Feng FY, Showalter TN, et al: Genomic prostate cancer classifier predicts biochemical failure and metastases in patients after postoperative radiation therapy. Int J Radiat Oncol Biol Phys 89: 1038-1046, 2014

13. Den RB, Yousefi K, Trabulsi EJ, et al: Genomic classifier identifies men with adverse pathology after radical prostatectomy who benefit from adjuvant radiation therapy. J Clin Oncol 33:944-951, 2015

14. Erho N, Crisan A, Vergara IA, et al: Discovery and validation of a prostate cancer genomic classifier that predicts early metastasis following radical prostatectomy. PLoS One 8:e66855, 2013

15. Karnes RJ, Bergstralh EJ, Davicioni E, et al: Validation of a genomic classifier that predicts metastasis following radical prostatectomy in an at risk patient population. J Urol 190:2047-2053, 2013

16. Klein EA, Yousefi $K$, Haddad Z, et al: A genomic classifier improves prediction of metastatic disease within 5 years after surgery in node-negative high-risk prostate cancer patients managed by radical prostatectomy without adjuvant therapy. Eur Urol 67: 778-786, 2015

17. Ross $A E$, Johnson MH, Yousefi K, et al: Tissuebased genomics augments post-prostatectomy risk stratification in a natural history cohort of intermediateand high-risk men. Eur Urol 69:157-165, 2016

18. Yamoah K, Johnson MH, Choeurng V, et al: Novel biomarker signature that may predict aggressive disease in African American men with prostate cancer. J Clin Oncol 33:2789-2796, 2015

19. Abdollah F, Suardi N, Cozzarini C, et al: Selecting the optimal candidate for adjuvant radiotherapy after radical prostatectomy for prostate cancer: A long-term survival analysis. Eur Urol 63: 998-1008, 2013
20. Collins GS, Reitsma JB, Altman DG, et al: Transparent Reporting of a multivariable prediction model for Individual Prognosis or Diagnosis (TRIPOD): The TRIPOD statement. Ann Intern Med 162: 55-63, 2015

21. Freedland SJ, Choeurng V, Howard L, et al: Utilization of a genomic classifier for prediction of metastasis following salvage radiation therapy after radical prostatectomy. Eur Urol 70:588-596, 2016

22. Lockstone HE: Exon array data analysis using Affymetrix power tools and $\mathrm{R}$ statistical software. Brief Bioinform 12:634-644, 2011

23. Piccolo SR, Sun Y, Campbell JD, et al: A singlesample microarray normalization method to facilitate personalized-medicine workflows. Genomics 100: 337-344, 2012

24. McShane LM, Altman DG, Sauerbrei W, et al: Reporting recommendations for tumor marker prognostic studies (REMARK). J Natl Cancer Inst 97: 1180-1184, 2005

25. Vickers AJ, Sjoberg DD: Guidelines for reporting of statistics in European Urology. Eur Urol 67:181-187, 2015

26. Gray RJ: A class of K-sample tests for comparing the cumulative incidence of a competing risk. Ann Stat 16:1141-1154, 1988

27. Firth D: Bias reduction of maximum likelihood estimates. Biometrika 80:27-38, 1993

28. Heagerty PJ, Lumley T, Pepe MS: Timedependent ROC curves for censored survival data and a diagnostic marker. Biometrics 56:337-344, 2000

29. D'Agostino RB, Nam B-H: Evaluation of the performance of survival analyses models: Discrimination and calibration measures, Balakrishnan N, Rao C, (eds): Handbook of Statistics. Amsterdam, the Netherlands, Elsevier BV, 2004, pp 1-25

30. Altman DG, Andersen PK: Calculating the number needed to treat for trials where the outcome is time to an event. BMJ 319:1492-1495, 1999

31. Hayman JA, Fairclough DL, Harris JR, et al: Patient preferences concerning the trade-off between the risks and benefits of routine radiation 
therapy after conservative surgery for early-stage breast cancer. J Clin Oncol 15:1252-1260, 1997

32. Parker C, Clarke N, Logue J, et al: RADICALS

(Radiotherapy and Androgen Deprivation in Combination after Local Surgery). Clin Oncol (R Coll Radiol) 19:167-171, 2007

33. Richaud $P$, Sargos $P$, Henriques de Figueiredo $B$, et al: Postoperative radiotherapy of prostate cancer [in French]. Cancer Radiother 14:500-503, 2010

34. Pearse M, Fraser-Browne C, Davis ID, et al: A phase III trial to investigate the timing of radiotherapy for prostate cancer with high-risk features: Background and rationale of the Radiotherapy - Adjuvant Versus Early Salvage (RAVES) trial. BJU Int 113:7-12, 2014 (suppl 2)

35. Isbarn H, Giannarini G: Re: Genomic classifier identifies men with adverse pathology after radical prostatectomy who benefit from adjuvant radiation therapy. Eur Urol 68:337-338, 2015

36. Loblaw DA, Virgo KS, Nam R, et al: Initial hormonal management of androgen-sensitive metastatic, recurrent, or progressive prostate cancer: 2006 update of an American Society of Clinical Oncology practice guideline. J Clin Oncol 25:1596-1605, 2007
37. Wong YN, Freedland S, Egleston B, et al: Role of androgen deprivation therapy for nodepositive prostate cancer. J Clin Oncol 27:100-105, 2009

38. Messing EM, Manola J, Yao J, et al: Immediate versus deferred androgen deprivation treatment in patients with node-positive prostate cancer after radical prostatectomy and pelvic lymphadenectomy. Lancet Oncol 7:472-479, 2006

39. Abdollah F, Karnes RJ, Suardi N, et al: Impact of adjuvant radiotherapy on survival of patients with node-positive prostate cancer. J Clin Oncol 32: 3939-3947, 2014

\section{Affiliations}

Deepansh Dalela, Mani Menon, and Firas Abdollah, Henry Ford Health System, Detroit, MI; María Santiago-Jiménez, Kasra Yousefi, and Elai Davicioni, GenomeDx Biosciences, Vancouver, British Columbia, Canada; R. Jeffrey Karnes, Mayo Clinic, Rochester, MN; Ashley E. Ross, Johns Hopkins Hospital, Baltimore, MD; Adam P. Dicker and Robert B. Den, Thomas Jefferson University, Philadelphia, PA; Stephen J. Freedland, Cedars-Sinai Medical Center, Los Angeles, CA; Edward M. Schaeffer, Northwestern University Feinberg School of Medicine, Chicago, IL; and Alberto Briganti, Vita Salute San Raffaele Hospital, Milan, Italy.

\section{Support}

A.E.R. is supported by a Prostate Cancer Foundation Young Investigator Award and a Department of Defense Physician Research Training Award. 


\section{AUTHORS' DISCLOSURES OF POTENTIAL CONFLICTS OF INTEREST}

Genomic Classifier Augments the Role of Pathological Features in Identifying Optimal Candidates for Adjuvant Radiation Therapy in Patients With Prostate Cancer: Development and Internal Validation of a Multivariable Prognostic Model

The following represents disclosure information provided by authors of this manuscript. All relationships are considered compensated. Relationships are self-held unless noted. I = Immediate Family Member, Inst = My Institution. Relationships may not relate to the subject matter of this manuscript. For more information about ASCO's conflict of interest policy, please refer to www.asco.org/rwc or ascopubs.org/jco/site/ifc.

Deepansh Dalela

No relationship to disclose

María Santiago-Jiménez

Employment: GenomeDx Biosciences

Kasra Yousefi

Employment: GenomeDx Biosciences

Travel, Accommodations, Expenses: GenomeDx Biosciences

\section{R. Jeffrey Karnes}

Research Funding: GenomeDx Biosciences

Travel, Accommodations, Expenses: GenomeDx Biosciences

\section{Ashley E. Ross}

Employment: GenomeDx Biosciences

Stock or Other Ownership: GenomeDx Biosciences

Robert B. Den

Consulting or Advisory Role: GenomeDx Biosciences Speakers' Bureau: Bayer

Research Funding: Medivation/Astellas, GenomeDx Biosciences

Travel, Accommodations, Expenses: GenomeDx Biosciences

Stephen J. Freedland

Stock or Other Ownership: Armune Bioscience, Parallel6

Consulting or Advisory Role: Astellas Pharma, Medivation, Janssen Biotech, Dendreon, MDxHealth, Sanofi, Bayer, GenomeDx Biosciences, Armune Bioscience, Parallel6

Research Funding: Dendreon (Inst), Bayer (Inst), Amgen (Inst), Janssen Biotech (Inst), Myriad Genetics (Inst), GenomeDx Biosciences (Inst), Mitomics (Inst), Metabolon (Inst), POM Wonderful (Inst), Progenika (Inst)

Travel, Accommodations, Expenses: Sanofi, Myriad Genetics, GenomeDx Biosciences

\section{Edward M. Schaeffer \\ Honoraria: GenomeDx Biosciences}

\section{Adam P. Dicker}

Consulting or Advisory Role: Merck, Glenview Consulting, Johnson \& Johnson

Travel, Accommodations, Expenses: Merck, Agios

Other Relationship: NRG Oncology, Department of Defense-Prostate Cancer Research Program

\section{Mani Menon}

No relationship to disclose

\section{Alberto Briganti}

Honoraria: Astellas Pharma, Ferring, Janssen-Cilag

Consulting or Advisory Role: Astellas Pharma, OPKO Health, MDxHealth, Bayer

Research Funding: Sandoz

Elai Davicioni

Employment: GenomeDx Biosciences

Leadership: GenomeDx Biosciences

Stock or Other Ownership: GenomeDx Biosciences

Patents, Royalties, Other Intellectual Property: Cancer diagnostics using biomarkers 20140066323

Travel, Accommodations, Expenses: GenomeDx Biosciences

Firas Abdollah

Consulting or Advisory Role: GenomeDx Biosciences

Travel, Accommodations, Expenses: GenomeDx Biosciences 


\section{Appendix}

Given the retrospective nature of the study, a formal sample-size calculation was not performed. A complete-case analytic approach was used; 11 patients were excluded from the study because of missing clinical or outcomes data.

\section{Five-Year Cumulative Incidence of Patients With Clinical Recurrence Undergoing Initial Observation Versus Upfront Adjuvant Radiotherapy}

Primary analyses. The 5-year cumulative incidence of clinical recurrence (CR) was 2.0\% (95\% CI, $0.0 \%$ to $4.7 \%$ ) in patients who received adjuvant radiotherapy (aRT) versus $9.1 \%$ (95\% CI, 6.2\% to $12.0 \%)$ in initial observation patients. At 5 years, the CR rates were $0.9 \%, 4.3 \%, 14.9 \%$, and $45.4 \%$ in patients with risk scores of $0,1,2$, and $3-4$, respectively. The 5-year CR rate was $0.0 \%$ versus $2.8 \%$ in patients with a risk score $<2(P=.18$; Fig $4 \mathrm{~A})$, whereas in patients with a risk score $\geq 2$, the 5 -year CR rate was $10.1 \%$ v 27.4\% $(P=.012$; Fig 4B).

Post hoc analyses (excluding all men with lymph node invasion). At 5 years, the CR rates were $0.9 \%, 4.5 \%, 15.6 \%$, and $42.9 \%$ in patients with risk scores of $0,1,2$, and 3, respectively. The 5-year CR rate was $0.0 \% v 2.9 \%$ in patients with a risk score $<2(P=.2)$, and $10.6 \% v 21.9 \%$ in patients with a risk score $\geq 2(P=.04)$.

\section{Results of Sensitivity Analyses After Excluding All Men With Lymph Node Invasion on Pathology}

Independent risk factors for CR were pathologic stage pT3b/T4 (hazard ratio [HR], 2.65), pathologic Gleason score 8 to 10 (HR, 3.85) and high Decipher score (HR, 2.90; all $P<.04)$. Patients treated with aRT had a $68 \%$ lower CR risk than their counterparts treated with initial observation $(P=.009)$. The predictive accuracy of the model was $82 \%(v 77 \%$ and $74 \%$ for the clinicopathologic and Decipher-only models, respectively) and showed favorable calibration characteristics (data not shown). The proportion of patients with risk scores of $0,1,2$, and 3 was 238 (50.9\%), 141 (30.1\%), 77 (16.5\%), and 12 (2.6\%). At 10 years, the CR rates were $5.6 \%, 13.1 \%, 29.6 \%$, and $42.9 \%$ in patients with risk scores of $0,1,2$, and 3 , respectively $(P<.001)$. In patients treated with aRT versus initial observation, the 10 -year CR rate was $3.5 \% v 9.6 \%$ in patients with a risk score $<2(P=.2)$, and $10.6 v$ $37.2 \%$ in patients with a risk score $\geq 2(P=.04)$.
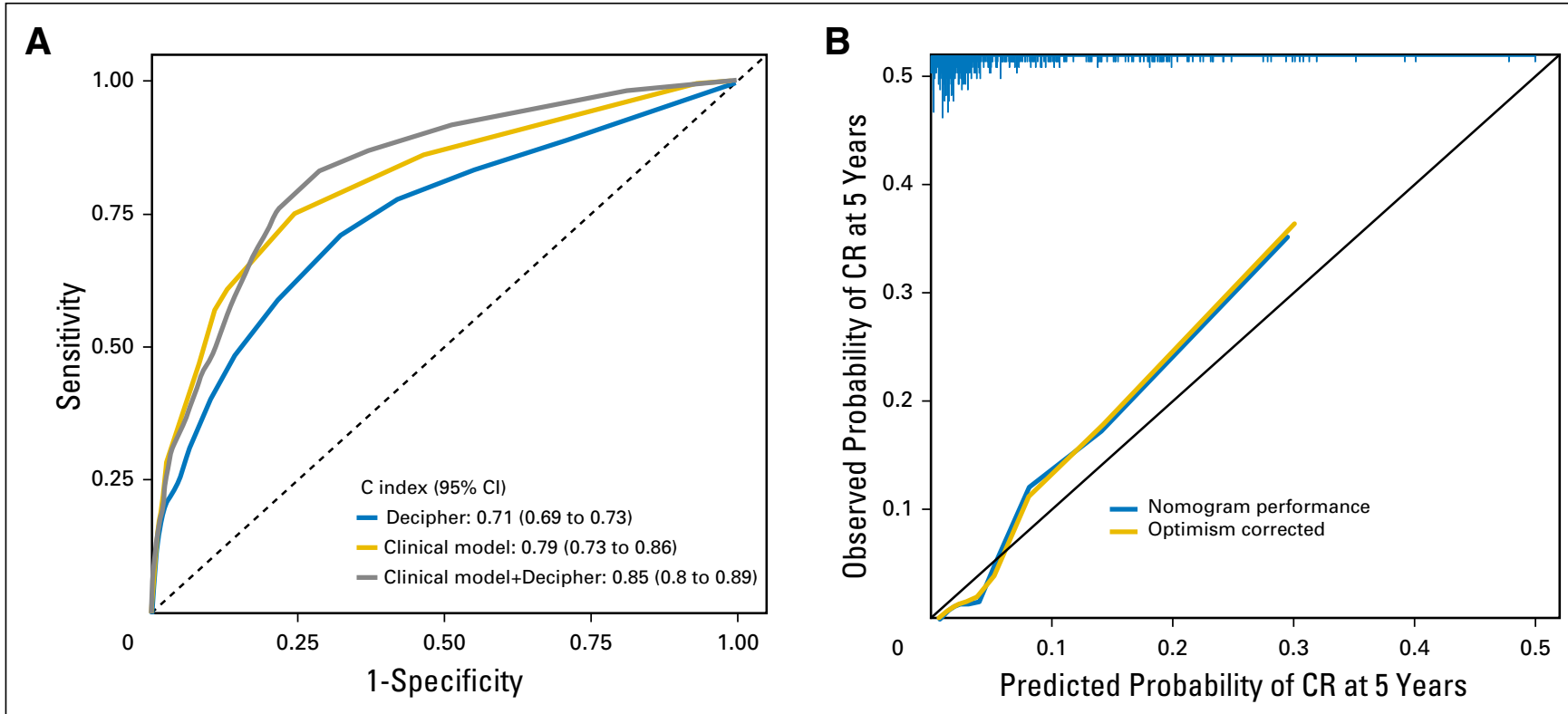

Fig A1. (A) Discrimination curve for the nomogram predicting clinical recurrence (CR) in patients with adverse pathologic features after radical prostatectomy, compared

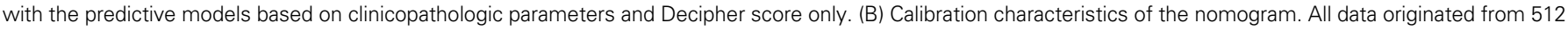

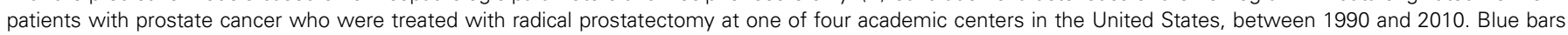
represent the frequency of the 5-year predicted probability of clinical recurrence. Both graphs were generated based on the 5-year end point. 


\begin{tabular}{|c|c|c|c|}
\hline Section/Topic & Item & Checklist Item & Page \\
\hline \multicolumn{4}{|l|}{ Title and abstract } \\
\hline Title & 1 & $\begin{array}{l}\text { Identify the study as developing and/or validating a multivariable } \\
\text { prediction model, the target population, and the outcome to } \\
\text { be predicted }\end{array}$ & 1 \\
\hline Abstract & 2 & $\begin{array}{l}\text { Provide a summary of objectives, study design, setting, } \\
\text { participants, sample size, predictors, outcome, statistical } \\
\text { analysis, results, and conclusions }\end{array}$ & 1 \\
\hline \multicolumn{4}{|c|}{, } \\
\hline \multirow[t]{2}{*}{ Background and objectives } & 3a & $\begin{array}{l}\text { Explain the medical context (including whether diagnostic or } \\
\text { prognostic) and rationale for developing or validating the } \\
\text { multivariable prediction model, including references to } \\
\text { existing models }\end{array}$ & $1-2$ \\
\hline & $3 b$ & $\begin{array}{l}\text { Specify the objectives, including whether the study describes } \\
\text { the development or validation of the model or both }\end{array}$ & $2-3$ \\
\hline \multicolumn{4}{|c|}{ (a) } \\
\hline \multirow[t]{2}{*}{ Source of data } & $4 a$ & $\begin{array}{l}\text { Describe the study design or source of data (eg, randomized } \\
\text { trial, cohort, or registry data), separately for the development } \\
\text { and validation data sets, if applicable }\end{array}$ & 2-3, Fig 1 \\
\hline & $4 \mathrm{~b}$ & $\begin{array}{l}\text { Specify the key study dates, including start of accrual; end of } \\
\text { accrual; and, if applicable, end of follow-up }\end{array}$ & $2-3$ \\
\hline \multirow[t]{3}{*}{ Participants } & $5 a$ & $\begin{array}{l}\text { Specify key elements of the study setting (eg, primary care, } \\
\text { secondary care, general population) including number and } \\
\text { location of centers }\end{array}$ & 2-3, Fig 1 \\
\hline & $5 b$ & Describe eligibility criteria for participants & 2-3, Fig 1 \\
\hline & $5 c$ & Give details of treatments received, if relevant & 3 \\
\hline \multirow[t]{2}{*}{ Outcome } & $6 a$ & $\begin{array}{l}\text { Clearly define the outcome that is predicted by the prediction } \\
\text { model, including how and when assessed }\end{array}$ & 3 \\
\hline & $6 b$ & $\begin{array}{l}\text { Report any actions to blind assessment of the outcome to be } \\
\text { predicted }\end{array}$ & 3 \\
\hline \multirow[t]{2}{*}{ Predictors } & $7 a$ & $\begin{array}{l}\text { Clearly define all predictors used in developing or validating the } \\
\text { multivariable prediction model, including how and when they } \\
\text { were measured }\end{array}$ & 3 \\
\hline & $7 \mathrm{~b}$ & $\begin{array}{l}\text { Report any actions to blind assessment of predictors for the } \\
\text { outcome and other predictors }\end{array}$ & 3 \\
\hline Sample size & 8 & Explain how the study size was arrived at & Sup App \\
\hline Missing data & 9 & $\begin{array}{l}\text { Describe how missing data were handled (eg, complete-case } \\
\text { analysis, single imputation, multiple imputation) with details } \\
\text { of any imputation method }\end{array}$ & Sup App, Fig 1 \\
\hline \multirow[t]{3}{*}{ Statistical analysis methods } & $10 \mathrm{a}$ & Describe how predictors were handled in the analyses & 3 \\
\hline & $10 \mathrm{~b}$ & $\begin{array}{l}\text { Specify type of model, all model-building procedures (including } \\
\text { any predictor selection), and method for internal validation }\end{array}$ & 3 \\
\hline & $10 d$ & $\begin{array}{l}\text { Specify all measures used to assess model performance and, if } \\
\text { relevant, to compare multiple models }\end{array}$ & 3 \\
\hline Risk groups & 11 & Provide details on how risk groups were created, if done & 3 \\
\hline \multicolumn{4}{|c|}{ 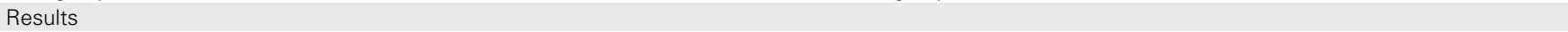 } \\
\hline \multirow[t]{2}{*}{ Participants } & $13 a$ & $\begin{array}{l}\text { Describe the flow of participants through the study, including } \\
\text { the number of participants with and without the outcome } \\
\text { and, if applicable, a summary of the follow up time. A diagram } \\
\text { may be helpful }\end{array}$ & Fig 1 \\
\hline & $13 \mathrm{~b}$ & $\begin{array}{l}\text { Describe the characteristics of the participants (basic } \\
\text { demographics, clinical features, available predictors), } \\
\text { including the number of participants with missing data for } \\
\text { predictors and outcome }\end{array}$ & 3, Table 1 \\
\hline \multirow[t]{2}{*}{ Model development } & $14 a$ & $\begin{array}{l}\text { Specify the number of participants and outcome events in each } \\
\text { analysis }\end{array}$ & $3-4$, Figs 3 and 4 \\
\hline & $14 b$ & $\begin{array}{l}\text { If done, report the unadjusted association between each } \\
\text { candidate predictor and outcome }\end{array}$ & Table 2, Sup Table 1 \\
\hline \multirow[t]{2}{*}{ Model specification } & $15 a$ & $\begin{array}{l}\text { Present the full prediction model to allow predictions for } \\
\text { individuals (ie, all regression coefficients, and model } \\
\text { intercept or baseline survival at a given time point) }\end{array}$ & Fig 2, SupTable 1 \\
\hline & $15 \mathrm{~b}$ & Explain how to the use the prediction model & Fig 2 \\
\hline Model performance & 16 & $\begin{array}{l}\text { Report performance measures (with } \mathrm{Cls} \text { ) for the prediction } \\
\text { model }\end{array}$ & Sup Fig 1 \\
\hline \multicolumn{4}{|c|}{ 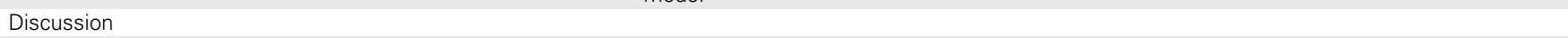 } \\
\hline Limitations & 18 & $\begin{array}{l}\text { Discuss any limitations of the study (such as nonrepresentative } \\
\text { sample, few events per predictor, missing data) }\end{array}$ & 8 \\
\hline Interpretation & $19 b$ & $\begin{array}{l}\text { Give an overall interpretation of the results, considering } \\
\text { objectives, limitations, and results from similar studies, and } \\
\text { other relevant evidence }\end{array}$ & $5-7$ \\
\hline \multirow[t]{2}{*}{ Implications } & 20 & $\begin{array}{l}\text { Discuss the potential clinical use of the model and implications } \\
\text { for future research }\end{array}$ & $5-7$ \\
\hline & & (continued on following page) & \\
\hline
\end{tabular}


Table A1. Transparent Reporting of a Multivariable Prediction Model for Individual Prognosis or Diagnosis Checklist ${ }^{20}$ (continued)

\begin{tabular}{|c|c|c|c|}
\hline Section/Topic & Item & Checklist Item & Page \\
\hline \multicolumn{4}{|l|}{ Other information } \\
\hline Supplementary information & 21 & $\begin{array}{l}\text { Provide information about the availability of supplementary } \\
\text { resources, such as study protocol, Web calculator, and data } \\
\text { sets }\end{array}$ & $\mathrm{N} / \mathrm{A}$ \\
\hline Funding & 22 & $\begin{array}{l}\text { Give the source of funding and the role of the funders for the } \\
\text { current study }\end{array}$ & $9-10$ \\
\hline
\end{tabular}

NOTE: We recommend using the Transparent Reporting of a Multivariable Prediction Model for Individual Prognosis or Diagnosis (TRIPOD) checklist in conjunction with the TRIPOD Explanation and Elaboration document.

Abbreviations: App, appendix; N/A, not applicable; Sup, supplement.

\begin{tabular}{|c|c|c|c|c|}
\hline \multirow[b]{2}{*}{ Variable } & \multicolumn{2}{|c|}{ Univariate Model } & \multicolumn{2}{|c|}{ Multivariate Model } \\
\hline & $\mathrm{HR}(95 \% \mathrm{Cl})$ & $P$ & $\mathrm{HR}(95 \% \mathrm{Cl})$ & $P$ \\
\hline \multicolumn{5}{|l|}{ Pathologic stage } \\
\hline рТ3a ( $v$ pT2) & 2.63 (1.11 to 7.45$)$ & .03 & 1.98 (0.8 to 5.76$)$ & .15 \\
\hline pT3b/pT4 ( $v$ pT2) & 5.97 (2.64 to 16.5$)$ & $<.001$ & 3.4 (1.39 to 9.84$)$ & .006 \\
\hline Pathologic Gleason score (8-10 $v \leq 7)$ & 5.07 (3.07 to 8.53 ) & $<.001$ & $3.33(1.94$ to 5.8$)$ & $<.001$ \\
\hline Lymph node invasion & 4.49 (2.48 to 7.72 ) & $<.001$ & 2.28 (1.16 to 4.3$)$ & .02 \\
\hline Surgical margins & 0.97 (0.58 to 1.66$)$ & .9 & 1.69 (1 to 2.95$)$ & .05 \\
\hline Adjuvant radiotherapy & 0.29 (0.1 to 0.68$)$ & .003 & 0.32 (0.1 to 0.77$)$ & .008 \\
\hline Adjuvant hormonal therapy & 1.75 (0.9 to 3.17$)$ & .1 & $0.62(0.3$ to 1.21$)$ & .17 \\
\hline Decipher score (per 0.1-unit increase) & $1.41(1.24$ to 1.61$)$ & $<.001$ & 1.25 (1.09 to 1.44$)$ & .002 \\
\hline
\end{tabular}

NOTE. For purposes of model building, we excluded preoperative prostate-specific antigen level as a covariate in this regression model to avoid overfitting of the data. Data are from four academic centers in the United States, 1990 to 2010.

Abbreviation: $\mathrm{HR}$, hazard ratio. 